\title{
Coupled and Stand-alone Regional Climate Modeling of Intensive Storms in Western Canada
}

\author{
Kai Ernn Gan ${ }^{1}$, Vijay Singh², Thian $\mathrm{Gan}^{3}$, Chun Chao Kuo ${ }^{3}$, and Holger Schüttrumpf ${ }^{4}$ \\ ${ }^{1}$ Texas A and M University College Station \\ ${ }^{2}$ Texas A \& M University \\ ${ }^{3}$ University of Alberta \\ ${ }^{4}$ RWTH Aachen
}

January 19, 2021

\begin{abstract}
A coupled atmospheric-hydrologic system models the complex interactions between the land surface and the atmospheric boundary layer, and the water-energy cycle from groundwater across the land surface to the top of the atmosphere. A regional climate model called WRF (Weather Research Forecasting) was coupled with a land surface scheme (Noah) to simulate intensive storms in central Alberta, Canada. Accounting for the land-atmosphere feedback enhances the predictability of the fine-tuned WRF-Noah system. Soil moisture, vegetation, and land surface temperature influence latent and sensible heat fluxes, and modulate both thermal and dynamical characteristics of land and lower atmosphere. WRF was set up in a two-way, threedomain nested framework so that the output of the outermost domain (D1) was used to run the second domain (D2) and the output of D2 was used to run the innermost domain (D3). In two-way nesting, D3 and D2 provide the feedback to their outer domains (D2 and D1), respectively. D3 was set at a 3-km resolution adequate to simulate convective storms. WRF-Noah was forced with climate outputs from Global Climate Models (GCMs) for the baseline period 1980-2005. A quantile-quantile bias correction method and a regional frequency analysis were applied to develop intensity-duration-frequency (IDF) curves from precipitation simulated by WRF-Noah. The simulated baseline precipitation of central Alberta agreed well with observed rain gauge data of Edmonton. The 5th-generation NCAR mesoscale atmospheric model (MM5) was also set up in a 3-domain, but one-way nesting configuration. As expected, after bias correction, precipitation simulated by MM5 was less accurate than that simulated by WRF-Noah. For storms of short durations and return periods of more than 25 years, both MM5 driven by SRES climate scenarios of CMIP3 and WRF-Noah driven by RCP climate scenarios of CMIP5 projected storm intensities in central Alberta to increase from the base period to the 2050s, and to the 2080s.
\end{abstract}

\section{Hosted file}

HydrologicProcesses2020Main.pdf available at https://authorea.com/users/390303/articles/ 504677-coupled-and-stand-alone-regional-climate-modeling-of-intensive-storms-in-westerncanada

\section{Hosted file}

HydrologicProcesses2020Fig.pdf available at https://authorea.com/users/390303/articles/ 504677-coupled-and-stand-alone-regional-climate-modeling-of-intensive-storms-in-westerncanada 